\title{
DEVELOPMENT OF BULGARIAN HEALTHCARE AND SOCIAL CARE PERIODICALS - THEMATIC SUSTAINABILITY, EXCHANGE OF KNOWLEDGE AND EXPERIENCE
}

\author{
Venelin Terziev ${ }^{1}$ and Silva Vasileva ${ }^{2}$ \\ ${ }^{1}$ Full Member of the Russian Academy of Natural History, Professor, Eng., \\ D.Sc. (National Security), D.Sc. (Economics), D.Sc. (Social Activities), Ph.D. \\ Georgi Rakovski Military Academy, Sofia, Bulgaria \\ Kaneff University Hospital, Rousse, Bulgaria \\ vkterziev@gmail.com \\ ${ }^{2}$ Yordan Yovkov High School, Rousse, Bulgaria \\ silvastvasileva@gmail.com
}

\begin{abstract}
This report compares the publication policy of Bulgarian periodicals in the health and social care field from the dawn of their publication history in Bulgaria, namely the end of $19 \mathrm{c}$ and the beginning of $20 \mathrm{c}$ century, with periodicals from the year in which the COVID-19 pandemic took over the news and has become a leading topic not only in medical journals. The choice of the type and theme of information sources is determined by the present-day relevance of the topic and by the fact that the specialized periodicals are the most reliable momentary reflection of the science achievements in the respective field. Periodicals, depending on the goals set by the editorial team, are a platform for presenting the most current and sometimes avant-garde practices of specialists and an opportunity to satisfy the interests of regular readers on health topics. It is according to the target group that publications are divided into two main categories: scientific and popular science. Of course, there are also the so-called "mixed" editions, but as a rule, compromises in this direction lead to their limited longevity.
\end{abstract}

Keywords: developmen, Bulgarian periodicals, changes, publication policy.

\section{INTRODUCTION}

The pandemic caused by COVID-19 has changed many things in our lives. Uncertainty and ignorance of how one can and should react in such situation scared many people. But after the initial fear, the issue of everyone's health literacy came to the fore - from the child to the eldest residents, both for the student, and his teacher. Health literacy, as a right and obligation of each one of us, turned out to be a forgotten yet not waning an issue (Flaherty, 2013), and periodicals with the power of knowledge preserved over the years one of the opportunities to provide it in a timely manner to virtually everyone. The relevance of these publications and the materials published in them play a leading role in the selection of issues, authors and titles for the coverage of the respective topic among specialists and the general public. A principle valid in full force for the Bulgarian periodicals in the healthcare and social care field. Only relevant topics as per the needs and interests of the target groups and adequate, as a vision and format, publications of health professional organizations can provide access to reliable and up-to-date information, which, on the one hand, would better inform different groups of users on their own health status, and on the other hand - on the basis of reliable and timely information - to promote "healthy" doctor-patient relationships. In this context, the dynamics in the advance of topics and issues, as well as the craving to transmit the research and 
achievements results to its audience in a timely manner are the basis of sustainable publishing policy and visual transformation of publications while periodicals themselves are established as a significant factor in the formation processes of the population's health literacy, exchange of knowledge, experience and practices among specialists and last but not least - as an active participant in the formation process of provision of knowledge, incl. health as well.

\section{DEVELOPMENT OF BULGARIAN HEALTHCARE AND SOCIAL CARE PERIODICALS}

The situation with the spread of the coronavirus in the last year has maximally sharpened the public's sensitivity to the topic of health. The problems motivated researchers and specialists to look at documentary and archival sources for the historical development of Bulgarian healthcare and medical and social work, with a focus on the activities of Bulgarian health institutions and professional medical organizations, as well as their coverage in specialized medical publications (Bozhilova, 2012). Moreover, it brought to the fore issues related to the introduction of rules, norms and regulations in the healthcare field. Although in different forms, with different themes and from different points of view - this turned out to be a leading topic in each epoch duly reflected in the publication policy of scientific periodicals, which, in turn, conveys specific public sensitivity to documenting and give publicity to the most current topics of the day.

This report compares the publication policy of Bulgarian periodicals in the health and social care field from the dawn of their publication history in Bulgaria, namely the end of $19 \mathrm{c}$ and the beginning of $20 \mathrm{c}$ century, with periodicals from the year in which the COVID-19 pandemic took over the news and has become a leading topic not only in medical journals. The choice of the type and theme of information sources is determined by the present-day relevance of the topic and by the fact that the specialized periodicals are the most reliable momentary reflection of the science achievements in the respective field. Periodicals, depending on the goals set by the editorial team, are a platform for presenting the most current and sometimes avant-garde practices of specialists and an opportunity to satisfy the interests of regular readers on health topics. It is according to the target group that publications are divided into two main categories: scientific and popular science. Of course, there are also the so-called "mixed" editions, but as a rule, compromises in this direction lead to their limited longevity.

Some of the oldest Bulgarian medical periodicals are presented, on the pages of which the spread of medical and health knowledge can be traced, the introduction of uniform regulations in Bulgarian health care, as well as the processes of formation and building of health literacy among the population, while making a comparison with the latest editions with their respective visual transformation.

\subsection{Medical Publications from the End of $19 \mathrm{c}$ and Beginning of $20 \mathrm{c}$}

Encyclopedia Britannica defines magazines as printed collections of texts (essays, articles, poems, short stories), often illustrated, and published at regular intervals. Modern magazines have their origins in former pamphlets and almanacs (Britannica, 2021a). They had their heyday and popularity after the discovery and widespread introduction of book printing. Magazines, for the most part, are thematic and are aimed at a specific group of readers according to their interests, profession, age, gender, etc., but there are also those, aimed at the general public. They are published at different intervals, set by the editorial team.

Specialized medical publications in Bulgaria began to appear at the end of $19 \mathrm{c}$. These were mainly magazines printed in limited editions and distributed by subscription. Today, most of them are bibliographic rarities and can be found only in specialized archives and in the collections of scientific and large public libraries in the country, and there is no guarantee for the completeness of the publications there. The availability of the titles is a result not so much of purposeful selection, but of chance and foresight of individuals in compiling the respective collections. Copies of medical journals preserved today often bear the marks of repeated use and re-reading.

\subsubsection{Specialized Medical Publications}

The first monthly scientific medical journal in Bulgaria was entitled Medicine. Monthly Scientific Medical Journal. Its first issue was published in 1894 in the town of Lovech. The editors of the publication are two enthusiastic and dedicated doctors from the Lovech Hospital - Dr. Petar Orahovac and Dr. Stefan Vatev. Before the first issue was published, they sent letters to 320 of their colleagues from all over the country, informing them of the idea of publishing a medical journal and asking them to express their opinion. Unfortunately, few supported this initiative. They also differed in their opinion about the content - some believed that the magazine should be popular science, others - that it should be only scientific. The editors themselves believe that in order to satisfy the interests of medical professionals, the journal should be "scientific-special" without information of a "popular" nature. In the end, a compromise had been reached - to 
have an addendum with popular readings accompanying each magazine number, without violating its scientific status.

The specialized nature of the publication and the overall concept of the editors, namely - to publish "papers related to medicine in Bulgaria", led to the formation of permanent thematic sections. Bulgarian Medical Dictionary, presenting in alphabetical order the names of human anatomical organs, the names of various diseases (in Bulgarian and Latin), medicinal herbs, etc.; Bibliography - a section in which readers could find out about newly published medical literature, incl. and one available in the editorial office itself. There one could find a list of new drugs available for sale in pharmacies. The publishers' desire to provide contemporary and up-to-date information to their readers can be traced in the section Statements from various magazines. It described diseases that were not typical of our latitudes. News in medicine at home and abroad were also published in the Miscellaneous section. There one could find information about upcoming or past scientific forums in medicine, as well as topics discussed by foreign colleagues. On the pages of that magazine, doctors from all over the country shared their experience in treating patients with cholera, diphtheria, tuberculosis and others - the most common diseases at that time in Bulgaria (Rasheva, 2021b).

Based on the published materials, a conclusion can be made about the greatest medical danger during these years, namely cholera. Out of 68 articles, 14 were dedicated to that disease. Among them we find titles such as "A New Explanation of Natural Immunity Against Asian Cholera" by Dr. Klemperer, "Cholera and Measures" by Dr. M. Ivanov, which was published in two consecutive issues of the journal, information on the spread of the disease in Constantinople and others.

The magazine had been published for just one year in seven consecutive books (the first - February - March 1894, the last - January 1895. In her study Radka Rasheva - librarian in the "Local History" department of the Lovech library, wrote that the main reason for the termination of the publication became the departure of the two doctors from the city - Dr. Orahovac was appointed manager of the Plovdiv hospital, and Dr. Vatev went to work in Sofia, where he later became a professor (Rasheva, 2021b).

The specialized scientific journals also include Medical collection. Journal of Bulgarian Doctors. The publication focuses on sharing of health knowledge among the medical community in Bulgaria. Its editors were Dr. Georgi Zolotovich - one of the pioneers in the sanitary and hygienic business in Bulgaria, and Dr. Marin Rusev, who started the fight against tuberculosis in Bulgaria.

The magazine got published monthly, from 1895 to 1899. From the text on the cover: "Annual subscription. For the whole of Bulgaria 7 levs. For abroad - shipping costs are added." - We can make a conclusion about the ambition of the publishers to promote it not only in Bulgaria. The publications covered a wide range of diseases, with a predominance of tuberculosis, diseases of the respiratory system, nervous system, cancer, influenza, eye and dental diseases and others. A special attention had been given to information about drugs and remedies. Articles on folk and forensic medicine can be read. The target group to which the publication was addressed also explains the specialized statistics and information that can be found on its pages. These are the "Antidote Chart" (antidotes) approved by the Supreme Medical Council, statistics on "births and deaths in the cities of the Principality", the number of "outpatients examined by state and municipal doctors", as well as the "number of manifest and secret prostitutes who were in the Principality" and others. The issue of vaccination, so topical today, is also touched upon. In the book \# 5 of the magazine's second anniversary, an article was published on the occasion of the centenary of the smallpox vaccine discovery by the father of modern immunology - Edward Jenner.

Along with the medical research scope and consumers' interests from the late $19 \mathrm{c}$ and early $20 \mathrm{c}$, the then periodicals reveal the processes of introducing uniform regulations, rules and norms in Bulgarian health care and public health. The study of information and documentary health resources is a source of knowledge about management practices in the young Bulgarian state (Terziev, Vasileva, 2021c).

Notice of the Public Health Directorate was a monthly bulletin, an official printed body of the Central Health Administration, represented by the General Directorate of Public Health. It was published with some interruptions and under different names from 1903 to 1947. The original edition was published under the title Notices of the Civil Sanitary Directorate. The Notices as well as the Medical Collection was realized under the editorship of Dr. Marin Rusev - Deputy Director and Director of the Civil Sanitary Directorate. Dr. Rusev is one of the main authors of the Public Health Protection Act in Bulgaria from 1903, which for the first time established a clear structure and regulated the work of medical institutions in our country, protecting their accessibility and democratic nature. Graduated in medicine with a doctorate in Geneva, thanks to the efforts of Dr. Rusev in 1918 Bulgaria opened its Sofia University Medical Faculty. 
From 1904 to 1909 and in 1911 the magazine was published under the title Notices of Public Health Protection Directorate, then with the title Notice of Public Health Directorate, and from 1929 - Notices of the General Directorate of the People's; both editions were being published simultaneously in 1929 and 1930.

Prime placement in the bulletin had articles reflecting the activities of the Higher Health Administration General Directorate of Public Health, the Supreme Medical Council and some of the departments had been made available to the medical community and the public. Dr.Kamelia Bozhilova, in her doctoral dissertation "The Documentary Heritage of Health Administration and Health Professional Organizations in the Central State Archives (1879 - 1944)", considers Notice of Public Health Directorate a public archive where the work and development of the health institution during this period has been documented and preserved (Bozhilova, 2012).

Prescriptions, ordinances, etc. regulatory and instructions documents were published in each of the issues. Statistical data on the declared infectious-epidemic diseases in the country, the movement of the population in Bulgaria before, during and after the wars, the changes in the sanitary staff, decisions of the Supreme Medical Council, etc. were also regularly provided. As of present, it is worth noticing Prof. Dr. T. Petrov's report, published in book \# 7 and \# 8 of 1926, covering the topic of tuberculosis vaccination of children with BCG vaccine, as well as contraindications for the first and second vaccination by Dr. A. Grot of the Bavarian National Vaccination Institute (Terziev, Vasileva, 2021c).

On the pages of the Notice of Public Health Directorate one can trace the proposals for exemption of the poor from the payment of health care, the provision of free treatment of certain infectious diseases. The first steps had been taken to exempt some categories of employees from paid medical care. The publication was issued until 1947 and reflects the nature of health care management; today it can also be considered as a public archive documenting the development and activity of the Directorate of Public Health and the Supreme Medical Council.

Public Health is another monthly specialized periodical on "public health issues and accessible medicine". It was published from 1907 till 1915. The editor of the magazine was Dr. Dimo Todorov Burilkov. Having studied natural sciences in Odessa and medicine in Lausanne, Dr. Burilkov worked as a doctor in Sofia and had actively participated in enhancing health education and social activities. He was chairman of the Union of Sanitary Workers (1919 - 1939), general secretary of the Society for Fight against Tuberculosis (1932 1938), chairman of the Bulgarian Abstinence Federation (1933 - 1941).

A doctor by education as well as a public figure, Dr. Burilkov was committed to the implementation of unified state policies in the young Bulgarian health care, namely: organization of maternity care, sanitary policy, public confrontation of sexually transmitted diseases, organization of health services in villages and others. Narodno Zdorove (Public Healthcare) magazine had become a forum for the public and civic opinions of a number of Bulgarian doctors since the beginning of $20 \mathrm{c}$. Without strictly defined rubrics, each leading article was most often written by Dr. Dimo Burilkov himself, where he introduced and discussed proposed normative and legal changes related to public health, such as the issues of decentralization of hospital care, a bill for food products, law for protection of public health, sanitary draft law, regulations for the internal order of the administrative-household service in hospitals and shelters, organization of courses for midwives and many more (Bilyarski, 2021d). Aimed at a strictly specialized audience, doctors from all over the country published their papers in the magazine, sharing their experience in treating patients with cancer, jaundice, tuberculosis and other diseases that were among the most common in Bulgaria during that period.

Public Health does not reflect structural changes and management decisions of the health administration, but from its pages one can get an idea of the medical community professional requirements and scientific interests. Its main advantage is publishing free criticism and opinions on upcoming health acts. Like most specialized medical publications of this period, it served as a platform for professional controversy among the medical community and allows for free expression of opinions and criticism of health acts and laws. Documents relevant to the history of the medical society were published on its pages, containing opinions and criticism against the official sanitary authorities and health acts. With a clear sense of responsibility and duty to society, the publishers aimed to enhance the general health culture as well as the integration of the Bulgarian health system from the beginning of 20th century according to European requirements (Bozhilova, 2012).

\subsubsection{Popular Medical Publications}

Health literacy is the ability to receive, process and understand basic information and services to make appropriate health decisions. It manifests itself in a number of ways - from understanding the instructions on the drug package to filling out a consent form for vaccination (Centers for Disease Control and Prevention, 
2021e). There are a number of factors that influence its formation - family environment, value system, level of education and many more. Yet, an indisputable factor for its mass formation among the population are the popular editions, including the periodicals. Aimed at a completely different from the narrowly specialized target group of readers, popular magazines strive to reach the widest possible range of readers by presenting issues that are important for public and personal health in an accessible and understandable to the layman way.

One of the first publicly available medical journals in Bulgaria was Zdrave (Health) or Zdravie. Its first issue was published in 1902 in Vidin and kept being published until 1924. Over the years, the editors of the magazine had been Dr. Iv. Nenov, Dr. I. Petkov, I. Pushkarov, DS Balev and others. The publication maintained several permanent rubrics: General Hygiene and Sanitation, School Hygiene, Sanitation and Pedagogy, Private Hygiene, Diseases - their essence and treatment, Natural Sciences, Anatomy and Physiology, Psychology and others. The articles in the Miscellaneous Useful Tips section were especially popular, where one could find articles on the benefits of sports, on facial skin care, as well as useful tips on how to provide first aid and handle a gunshot wound.

The editors of the publication, directing it mainly to readers without knowledge in the field of medicine, skillfully used the names of celebrities to promote their ideas among readers. Such are the articles "Memories of L N Tolstoy. How He Quit Smoking" or "Alexandre Dumas fils' Hygiene"and others.

A first hand reviewing of the publication annual volumes, most relevant topics for those years have been identified. Thus, in 1906, tuberculosis was leading the list - a disease that at the beginning of the century was a real scourge for the population not only in Bulgaria. The introductory article is by Professor Gransche - one of Pasteur's followers - on anti-tuberculosis tactics in England, Germany and France. The editorial team of the magazine also included Dr. Iv. Nenov - author of one of the most detailed studies of tuberculosis, published in his paper of 1930 under the same name. Advice on high personal hygiene and a healthy lifestyle, including issues related to mental health, were presented in a popular and accessible language, which made Zdrave magazine one of the most widely read health periodicals in Bulgaria since the beginning of 20 c (Terziev, Vasileva, 2021c).

Medical-pedagogical Magazine for Health, Social and Educational Care for Children and Adolescents was a medical edition that was published without interruption from 1935 to 1944. Its editors were Dr. V. Shumanov and Angel Petrov. 70 specialists from all over the country were involved in the publication - doctors, pedagogues, psychologists, sociologists, prominent public figures and others. Aimed at the health and education of adolescents in our country, the publication strived to "fight for a healthy generation and a healthy people", which, according to the editorial team, was "the main motto of any modern state".

The edition had no strictly defined rubrics. The publication was structured so as to always provide articles by leading Bulgarian and foreign physicians, addressing issues of physical and mental health of children and adolescents, such as. The article by Dr. M. Geraskov "The Social Value of the Child", by Dr. D. Garvalov "Mental and Nervous Suffering in School Age" and others. A special place was given to school hygiene and hygiene of education and training ("Vacation and Hygiene of the Mind" by Prof. Dr. Asen Zlatarov, "Hygienic and Educational Importance of School Canteens" by Dr. Hristo Draganov), defective children and auxiliary medical and pedagogical institutes ("Children with Disabilities at Home and at School" by Geno Dochev, "How to Proceed in the Language Development Training of Mentally Retarded Children" by St. Traikov), legal care ("Compulsory Health Insurance for Students" (By Dr. Zah. Bochev), medical and pedagogical practices ("Methods of Public Assistance in Germany" by Raina Petkova), bibliography of new and useful publications on health issues, reviews and short scientific communiqués.

One of the editors - Dr. V. Shumanov, was a leading specialist in the first half of $20 \mathrm{c}$ in the field of school hygiene and devoted much of his life to working with children from auxiliary schools or as "Law on Public Education" of 1891 called them - "special schools". Under his editorship, in addition to Medical-Pedagogical Magazine, Medical-Pedagogical Library, Our Child Magazine, as well as School Hygiene - A Short Guide for Doctors, Teachers and Students, printed in Vol. 6 of 1942 Medical-Pedagogical Library, were also published.

The wide range of affiliates to the magazine, as well as the topics covered in it, are indisputable proof of the importance of hygiene and health education from an early age, as well as the role of each person in building a healthy society.

In the first years after the Liberation, the revivalist traditions in the editing of Bulgarian periodicals had been continued, especially with magazines, yet the strong influence of the Russian and European topographic tradition cannot be ignored. The development of a comprehensive content and design concept aimed to attract readership and keep the interest in the respective edition. Until the end of $19 \mathrm{c}$, despite the 
aspirations and attempts of the editorial teams to impose their recognizable and uniform as a visual stylistic design system, magazines, including medical ones, had approximately the same graphic design. In general, the publications follow the interests of a specific addressee: typography of the publication, title, choice of format, columns, inserted boxes, content page, rubrics, illustrations, graphics, font, and after 1902 , photographs (Stoimenova, 2018). The changes in the layout followed the economic and political processes in the country, which led to an increased interest in periodicals in general, namely - establishment of state administration and institutions, political parties, expansion of economic and cultural life, which resulted in increased number of educated and literate people.

Medical journals make no exception in this respect. Observations on publications from the end of $19 \mathrm{c}$ and the first half of $20 \mathrm{c}$ unequivocally reveal the tendency of medical periodicals to face the achievements of modern medicine, as well as the desire to provide information on leading regulations, standards and practices and their introduction in Bulgarian health care.

Initially started outside Sofia (the capital of Bulgaria), publishing activity gradually got concentrated in the capital city. Leading names in Bulgarian medicine took part as authors and affiliates. The periodicity of magazines varied and often depended on the number of respective publication subscribers. Financial instability or relocation of editors, most often to the capital, were among the most common reasons for interruption and suspension of publications.

\section{CONCLUSION}

Modern medicine is being vacated to contribute to national health care development by training qualified specialists in the field of medical sciences and improving preventive, curative and rehabilitation activities as well as health care in accordance with the universal values and national traditions in humane and tolerant treatment of man and his needs. Our country's membership in the European Union requires the implementation of a coherent policy in terms of improving the quality of life of modern man, including positive practices in the field of legislation, organization of health care and provision of accessible information in the wide range of health problems and modern achievements of medical science. In this respect, medical periodicals are a proven and established source of professional information on education, science-based prevention, treatment and rehabilitation of diseases and research in the field of medical sciences and the health system.

\section{REFERENCE LIST}

Flaherty, M. G. (2013). The Public Library as Health Information Resource?: Dissertation.

Bozhilova, KK. (2012). Documentary heritage of the health administration and health professional organizations in the Central State Archives (1879 - 1944): Author's abstract. Sofia: Sofia University St. Kliment Ohridski.

Britanica. (n.d.). (2021a). Newspapers \& Magazines. Excerpted from Britanica: https://www.britannica.com/topic/magazine-publishing.

Rasheva, R. (2021b). Lovech today.eu. Excerpted from Lovech today.eu:

https://lovechtoday.eu/prez-1894-g-v-lovech-izliza-parvata-knizhka-n/, 09/2021.

Terziev, V., Vasileva, S. (2021c). The public library as health information resource, 2021.

Bilyarski, C. V. (b. G.). (2021d). Dr. Vladimir Burilkov - the most famous journalist and publicist among the Thracian Bulgarians. Excerpted from All Bulgarians Together: http://www.sitebulgarizaedno.com/index.php?option=com_content\&view=article\&id=463:2012-09-1818-24-58\&catid=29:2010-04-24-09-14-13\&ltemid=61, 09/2021.

Centres for Disease Control and Prevention. (2021e). Excerpted from Health Literacy: https://www.cdc.gov/healthliteracy/learn/index.html, 09/2021.

Stoimenova, BV. (2018). Design of printed publications in the late $19 \mathrm{c}$ and early $20 \mathrm{c}(1878$-1944). Author's abstract. Sofia, Bulgaria. Downloaded on August 16th 2021, from: https://docplayer.bg/174216711\%D0\%B0-\%D0\%B2-\%D1\%82-\%D0\%BE-\%D1\%80-\%D0\%B5-\%D1\%84-\%D0\%B5-\%D1\%80$\%$ D0\%B0-\%D1\%82.html. 